\title{
Photocatalytic degradation of aqueous tetrahydrofuran, 1,4-dioxane, and their mixture with $\mathrm{TiO}_{2}$
}

\author{
Mehrab Mehrvar, ${ }^{1, \dagger}$ William A. Anderson, ${ }^{2}$ and Murray Moo-Young ${ }^{2}$ \\ ${ }^{1}$ Department of Chemistry, Biology and Chemical Engineering, Ryerson Polytechnic University, Toronto, \\ Ontario, Canada M5B 2K3 \\ ${ }^{2}$ Department of Chemical Engineering, University of Waterloo, Waterloo, Ontario, Canada N2L 3G1
}

\begin{abstract}
Photocatalytic degradation of tetrahydrofuran, 1,4-dioxane, and their mixture in a slurry photoreactor was studied. Using both GC/MS and ion chromatography (IC) methods, possible intermediates were detected and the reaction mechanism pathways for both compounds were proposed. Kinetic models were developed and the kinetic parameters were estimated using a statistical method of non-linear parameter estimation in which all experimental data were utilized. It was shown that tetrahydrofuran was disappeared via direct oxidation as well as hydroxyl radical attack. A modified Langmuir-Hinshelwood described the degradation behavior of tetrahydrofuran and the binary system. 1,4-Dioxane obeyed a simple Langmuir-Hinshelwood kinetic form in the single compound system.
\end{abstract}

\section{INTRODUCTION}

Photocatalysis, an advanced oxidation process (AOP), has shown promise as a route to destroy biologically recalcitrant organic pollutants completely to $\mathrm{CO}_{2}$, water, and inorganic compounds. While numerous publications in photocatalysis have dealt with the degradation of different aqueous organic compounds, fewer studies have been done on the photocatalytic degradation of tetrahydrofuran (THF), 1,4-dioxane (DIOX), and their mixture. Principles and mechanisms of photocatalysis have been reviewed in various papers (for example see $[1,2,3,4,5,6,7,8,9,10,11]$. It has been reported that organic pollutants and hydroxyl radicals may react either at the surface of the catalyst or in the bulk phase $[12,13]$. Even though the exact mechanisms of each step of the reaction are not always clear and little information on multicomponent systems is available, the literature indicates that forms of the LangmuirHinshelwood (LH) rate equation can predict the rate of reaction for component $i$ which is adsorbed competitively with other species $[12,14,15,16,17,18,19]$ such as:

$$
r_{i}=\frac{k_{i} K_{i} C_{i}}{1+K_{i} C_{i}+\sum_{j=1(j \neq i)}^{n} K_{j} C_{j}},
$$

where $-r_{i}=$ the reaction rate of the component $\mathrm{i}$ to be degraded, $\left[\mathrm{M} \mathrm{s}^{-1}\right]$;

$C_{i}=$ the concentration of the component $\mathrm{i},[\mathrm{M}]$;

$k_{i}=$ the reaction rate constant, [ $\mathrm{M} \mathrm{s}^{-1}$ ], a function of catalytic properties, catalyst loading, $\mathrm{pH}$, temperature, species present, and light intensity;

$K_{i}=$ the apparent binding constant, $\left[\mathrm{M}^{-1}\right]$, a function of the catalyst surface, reactants, and solvent properties;

$n=$ number of competing species.

THF and DIOX are used in large quantities as

† E-mail: mmehrvar@acs.ryerson.ca solvents and chemical bulk products, and are found in contaminated groundwater. THF and DIOX are industrial solvents used for dyes, oils, waxes, resins, cellulosic esters and ethers, and polyvinyl polymers $[20,21,22,23]$. The biodegradation of these pollutants is very slow or they are not biodegradable [24, 25, 26, 27, 28]. Consequently, an additional process may be necessary to degrade these contaminants. Therefore, the kinetics of the photocatalytic degradation of these compounds and their mixtures was studied to determine the feasibility of this technology for this application. The development of a rigorous kinetic model was of particular interest.

\section{MATERIALS AND METHODS}

The schematic diagram of the experimental setup is shown in Figure 1. The annular slurry photoreactor was constructed with two concentric borosilicate glass tubes. Light was provided by a UV lamp inside and six UV lamps around the photoreactor (TL20W/09N, Philips). They emit highly concentrated radiation between 320 and $390 \mathrm{~nm}$ with maximum peak at $350 \mathrm{~nm}$. By leaving a headspace, a reservoir was made to provide the required oxygen. The liquid in the reservoir was stirred magnetically to increase the mass transfer between the headspace and the liquid as well as to provide a homogeneous system. Before starting each run, the water was aerated to saturation using air. Dissolved oxygen was measured on line using a DO meter (YSI model 57). It was observed that during the course of the reaction there was sufficient dissolved oxygen in the system. The slurry was recirculated through the system using a magnetic drive pump. The temperature throughout the experiments was kept at $25 \pm 2{ }^{\circ} \mathrm{C}$ with a circulating water bath (NESLAB RTE 111).

The illumination zone of the photoreactor was $3.8 \mathrm{~L}$ and the total liquid volume used was $7.0 \mathrm{~L}$. Since the liquid was illuminated for only a fraction of the time it circulated in the system, the illumination time 


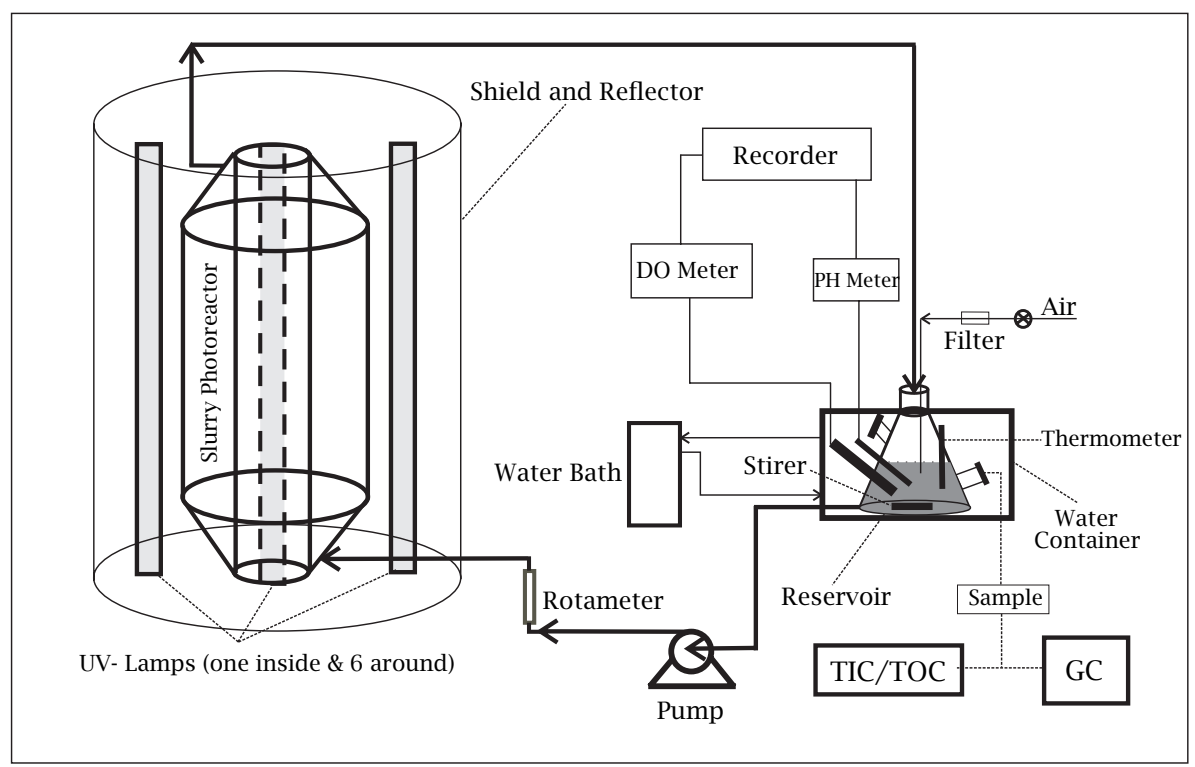

Figure 1. Schematic diagram of the slurry photoreactor set-up.

in this slurry photoreactor may be estimated as follows:

$$
t_{\text {Ill }}=\frac{3.8 \mathrm{~L}}{7.0 \mathrm{~L}}\left(t_{\text {run }}\right)=0.543\left(t_{\text {run }}\right) .
$$

The flow rate in this photoreactor was $12.1 \mathrm{~L} \mathrm{~min}^{-1}$. Since the total liquid used in this photoreactor was $7.0 \mathrm{~L}$ for each run, the time required for a pass was $0.58 \mathrm{~min}$. This slurry photoreactor was a recycling differential reactor since the conversion per pass in all cases was small $(<1 \%)$. This means that there could be no appreciable concentration gradient throughout the recycling system at any instant. Because of no through flow in this slurry photoreactor, this was essentially a batch photoreactor.

Identification of the intermediates produced during the course of reactions was carried out using a GC/MS (Hewlett Packard 5890 Series II, Avondale, PA with a Hewlett Packard 5971 Series with mass selective detector). Prior to testing, the samples were centrifuged at about $4500 \mathrm{rpm}$. Solid Phase MicroExtraction (SPME) was used to extract the aqueous samples for GC/MS analysis using $65 \mu \mathrm{m}$ carbowax/divinylbenzene which was partially crosslinked. This method was verified by analyzing known organic solutions such as THF and DIOX. Ion chromatography (IC) was used to identify possible organic acid intermediates, based on the method developed by Peldszus et al. [29]. Degussa P25 titanium dioxide (Degussa Corporation) was used as the photocatalyst.

\section{RESULTS AND DISCUSSION}

3.1. Dark reactions and photolysis. Dark and photolytic (noncatalytic) reactions were performed in the slurry photoreactor. A decrease in the concentration of parent compounds of less than $10 \%$ indicated that these reactions do not contribute to the photocatalytic degradation of THF and DIOX significantly. Therefore, it can be concluded that almost all the disappearance of organics in this study was solely a result of photocatalysis.

3.2. Tetrahydrofuran. The optimum $\mathrm{TiO}_{2}$ loading, $1.5 \mathrm{~g} \mathrm{~L}^{-1}$, was used in all experiments. The intermediates in the photocatalytic degradation of THF are summarized in Table 1. A few hypothesized intermediates that have not been detected but are believed to exist are also listed. Identification of organic acids as intermediates helps to achieve a better understanding of mechanisms in photocatalysis. Based on the relative retention time studies, acetic acid, formic acid, $\beta$ hydroxybutyric acid, and glycolic acid were detected and identified as THF intermediates. The IC analysis studies also showed that the amount of acetic acid and formic acid presented in the sample was in the range of $\mathrm{m} \mathrm{L}^{-1}$, whereas the amount of other organic acids were very low $\left(\mu \mathrm{g} \mathrm{L}^{-1}\right)$.

Table 1. Possible intermediates for the photocatalytic degradation of THF.

\begin{tabular}{lc}
\hline Intermediate & $\begin{array}{c}\text { Detection } \\
\text { method }\end{array}$ \\
\hline $\begin{array}{l}\text { 2(3H)-Furanone, dihydro- } \\
(\gamma \text {-Butyrolactone) }\end{array}$ & GC/MS \\
Succinic acid & GC/MS \\
Acetic acid & GC/MS \& IC \\
Formic acid & IC \\
$\beta$-Hydroxybutyric acid & IC \\
Glycolic acid & IC \\
2-Hydroxytetrahydrofuran & Hypothesized \\
Dihydro-5-hydroxy-2(3H)-furanone & Hypothesized \\
4-Oxobutanoic acid & Hypothesized \\
\hline
\end{tabular}




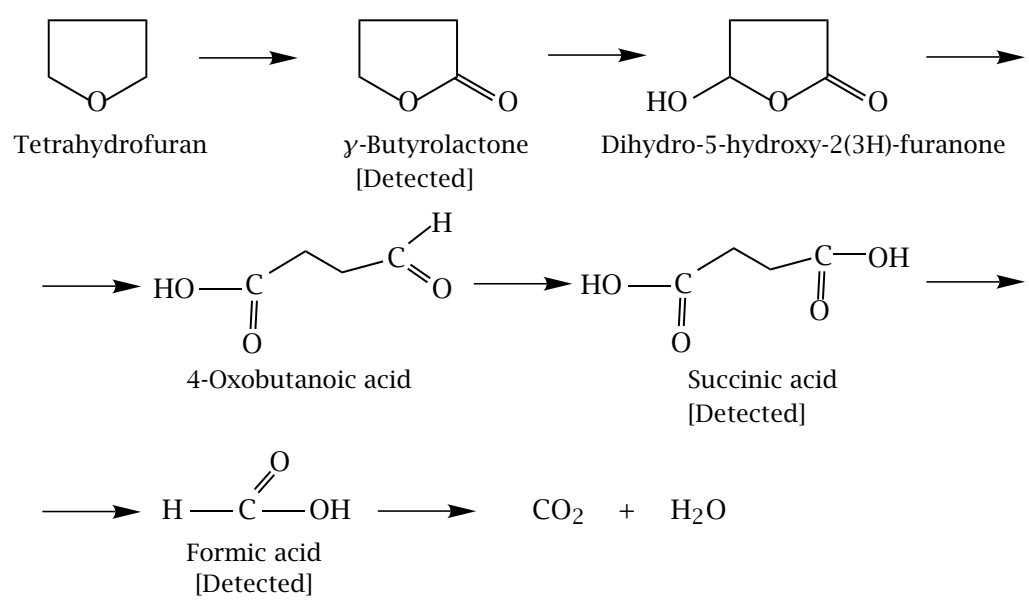

Figure 2. Proposed reaction mechanism for THF degradation.

THF reaction mechanisms. Identification of the intermediates in the photocatalytic degradation of THF leads to a proposed degradation pathway. The hypothetical reaction pathways for the photocatalytic degradation of THF are depicted in Figure 2. In this mechanism, THF is readily oxygenated to $\gamma$-butyrolactone (GBL). $\gamma$-Butyrolactone, in turn, is attacked by a hydroxyl radical, $\bullet \cdot \mathrm{OH}$, produced during the illumination of the titanium dioxide. Succinic acid and other organic acids such as formic and acetic acids are produced during the process, which are then eventually converted to $\mathrm{CO}_{2}$. The details of the reaction mechanisms and the kinetic model development for tetrahydrofuran are discussed in Appendix A.

Kinetic parameter estimation for degradation of THF. Dynamic model equations for the degradation of THF, developed in Appendix A, are shown in equations (A.37). To find the parameters in equations (A.37), a set of experimental trials with different initial THF concentrations was carried out. Applying all experimental data for different trials and using the statistical method outlined by Mehrvar et al. [30], the best point estimate kinetic parameters in the dynamic model for THF may be computed. Table 2 lists the parameter values estimated for the dynamic model in equations (A.37).

Table 2. THF kinetic parameters in dynamic model equations (A.37).

\begin{tabular}{cc}
\hline Compound & \multicolumn{1}{c}{$\begin{array}{c}\text { Parameters with 95\% } \\
\text { confidence levels }\end{array}$} \\
\hline \multirow{2}{*}{ THF } & $k_{\mathrm{app}}=(1.71 \pm 0.08) \times 10^{-2}\left[\mathrm{~min}^{-1}\right]$ \\
& $k_{\mathrm{THF}}=5.24 \pm 0.51\left[\mu \mathrm{Mmin}^{-1}\right]$ \\
& $K_{\mathrm{THF}}=(3.16 \pm 0.13) \times 10^{-2}\left[\mu \mathrm{M}^{-1}\right]$ \\
\hline \multirow{2}{*}{$\mathrm{GBL}$} & $k_{\mathrm{GBL}}=1.67 \pm 0.30\left[\mu \mathrm{Mmin}^{-1}\right]$ \\
& $K_{\mathrm{GBL}}=(3.3 \pm 1.4) \times 10^{-2}\left[\mu \mathrm{M}^{-1}\right]$ \\
\hline
\end{tabular}

Figure 3 shows a typical result for one of the runs in which THF followed the modified LH form in equations (A.37). The modified LH form described the exper- imental data for THF and its significant intermediate, GBL, well.

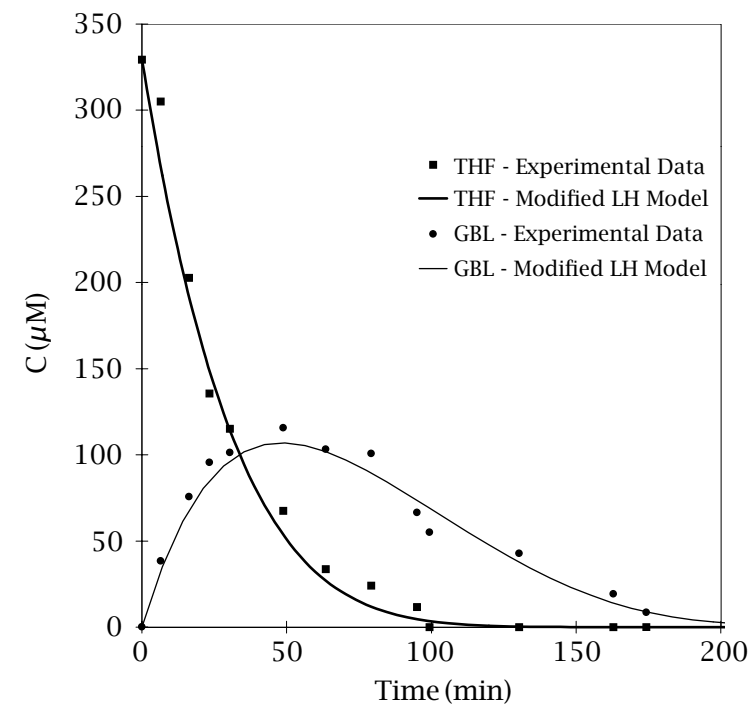

Figure 3. Photocatalytic degradation of THF along with its intermediate, $\gamma$-butyrolactone (GBL), in the slurry photoreactor; $C_{0, \mathrm{THF}}=329.4 \mu \mathrm{M}$.

A simplified LH model with no intermediates (equation 3) was applied to the experimental data in order to compare the LH with its modified form. The estimated kinetic parameters in equation (3) are shown in Table 3.

$$
-r_{i}=-\frac{d C_{i}}{d t}=\frac{k_{i} K_{i} C_{i}}{1+K_{i} C_{i}}
$$

For comparison, the conventional LH model considering one intermediate in the model as shown in equation (4) was also applied to the THF experimental data. The estimated parameters are summarized in Table 4. In the derivation of equations (4), it has been assumed that THF degradation occurs only via hydroxyl radical attacks while in the development of the modified LH model in equations (A.37), it had been assumed that THF disappearance proceeded via both hydroxyl 
radical attacks and direct oxidation.

$$
\begin{gathered}
-r_{\mathrm{THF}}=-\frac{d C_{\mathrm{THF}}}{d t}=\frac{k_{\mathrm{THF}} K_{\mathrm{THF}} C_{\mathrm{THF}}}{1+K_{\mathrm{THF}} C_{\mathrm{THF}}+K_{\mathrm{GBL}} C_{\mathrm{GBL}}}, \\
r_{\mathrm{GBL}}=\frac{d C_{\mathrm{GBL}}}{d t}=\frac{k_{\mathrm{THF}} K_{\mathrm{THF}} C_{\mathrm{THF}}-k_{\mathrm{GBL}} K_{\mathrm{GBL}} C_{\mathrm{GBL}}}{1+K_{\mathrm{THF}} C_{\mathrm{THF}}+K_{\mathrm{GBL}} C_{\mathrm{GBL}}} .
\end{gathered}
$$

Table 3. THF kinetic parameters considering no intermediates in the LH model equations (3).

\begin{tabular}{cc}
\hline Compound & $\begin{array}{c}\text { Parameters with 95\% } \\
\text { confidence levels }\end{array}$ \\
\hline \multirow{2}{*}{$\mathrm{THF}$} & $k_{\mathrm{THF}}=13.5 \pm 2.6\left[\mu \mathrm{Mmin}^{-1}\right]$ \\
& $K_{\mathrm{THF}}=(5.3 \pm 1.9) \times 10^{-3}\left[\mu \mathrm{M}^{-1}\right]$ \\
\hline
\end{tabular}

Table 4. THF kinetic parameters in LH model equations (4) considering GBL as its intermediate.

\begin{tabular}{cc}
\hline Compound & $\begin{array}{c}\text { parameters with 95\% } \\
\text { confidence levels }\end{array}$ \\
\hline \multirow{2}{*}{$\mathrm{THF}$} & $\left.k_{\mathrm{THF}}=46.3 \pm 7.8 \mu \mathrm{Mmin}^{-1}\right]$ \\
& $K_{\mathrm{THF}}=(8.84 \pm 0.60) \times 10^{-4}\left[\mu \mathrm{M}^{-1}\right]$ \\
\hline \multirow{2}{*}{$\mathrm{GBL}$} & $k_{\mathrm{GBL}}=6.80 \pm 0.86\left[\mu \mathrm{Mmin}^{-1}\right]$ \\
& $K_{\mathrm{GBL}}=(1.16 \pm 0.37) \times 10^{-2}\left[\mu \mathrm{M}^{-1}\right]$ \\
\hline
\end{tabular}

Although the modified LH model worked well for the photocatalytic mineralization of THF, it described the experimental data only in the lower concentration ranges (for example, $C_{0, \mathrm{THF}}=0-500 \mu \mathrm{M}$ ).

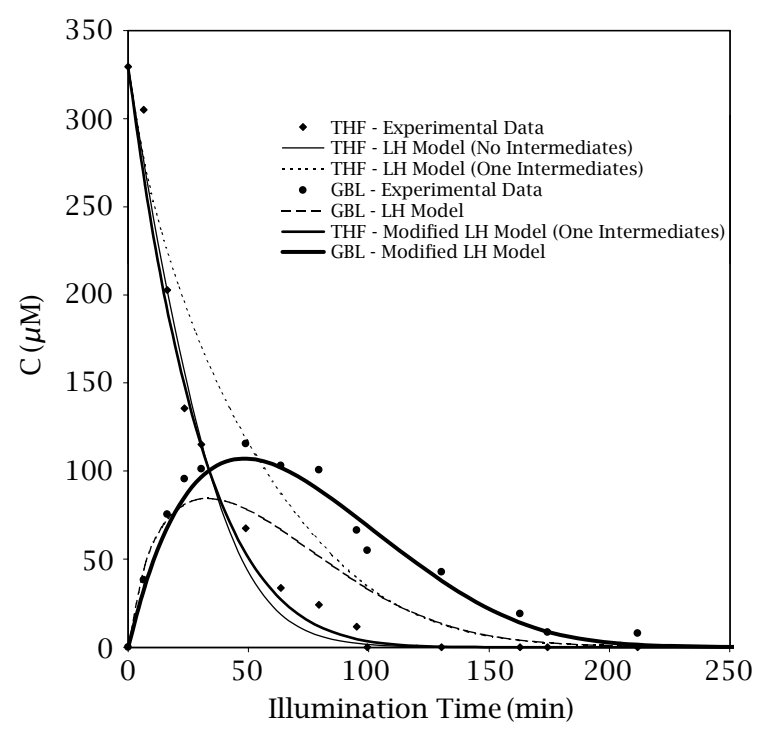

Figure 4. Comparison of the different models for the photocatalytic degradation of THF along with its intermediate, $\gamma$-butyrolactone (GBL), in the slurry photoreactor; $C_{0, \mathrm{THF}}=329.4 \mu \mathrm{M}$.

Figure 4 compares the different models for THF destruction. This figure illustrates that the LH model without any intermediates also describes the data well. This might be due to the fact that the measured concentrations of intermediates were low in low initial concentration ranges. On the other hand, the LH model with one intermediate (equations (4)) underestimated the data. For the higher concentration of THF, neither the modified LH model nor the LH model without any intermediates describe the experimental data well. In the higher concentration ranges for THF, the concentration of intermediates are sufficiently high such that the intermediate term in the denominator is necessary in the model. Also, in the higher concentration ranges, the disappearance of THF tends to be a zero order reaction. Consequently, the first term, which contributes the first order kinetics in the dynamic model of equations (A.37) was excluded. As Figure 5 depicts, the LH model with GBL as its intermediate (equations (4)), represented the experimental data in the higher concentration range. In contrast, the modified LH model and the LH model without any intermediates overestimated the experimental data

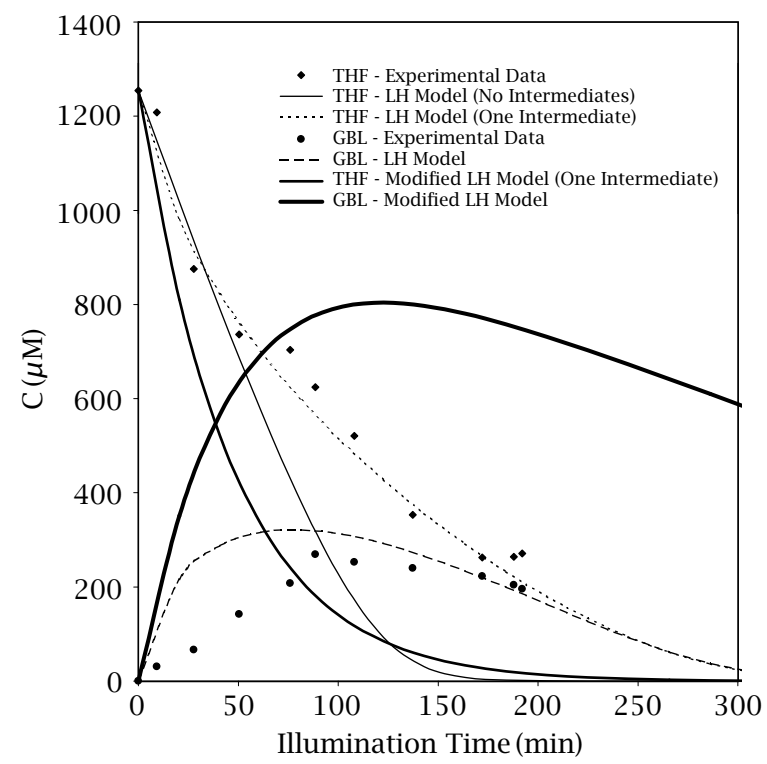

Figure 5. Comparison of the different models for the photocatalytic degradation of THF along with its intermediate, $\gamma$-butyrolactone (GBL), in the slurry photoreactor; $C_{0, \mathrm{THF}}=1254.38 \mu \mathrm{M}$.

3.3. 1,4-Dioxane. GC/MS and IC analyses for DIOX were performed using similar methods to those for THF analyses. Table 5 summarizes the results of possible intermediates identified for DIOX by both analytical procedures. 1,2-Ethanediol, diformate (EDD) was one of the significant intermediates detected in the photocatalytic mineralization of DIOX. This intermediate was also found as the significant intermediate of DIOX by two other research groups [31, 32]. However, its peak area ratio and hence, its concentration in all runs was low in comparison to the parent compound. EDD concentrations could not be quantified due to the lack of an available calibration standard. Acetic acid was another DIOX intermediate found through both GC/MS and IC analyses. The IC analysis showed that formic acid was present at $\mathrm{mg} \mathrm{L}^{-1}$ levels. Other organic acids such as acetic, glycolic, and $\beta$-hydroxybutyric acids were also detected and identified as DIOX intermediates. 
However, the concentrations of these three organic acids were low $\left(\mu \mathrm{g} \mathrm{L}^{-1}\right)$.

Table 5. Possible intermediates for the photocatalytic degradation of DIOX.

\begin{tabular}{lc}
\hline Intermediate & $\begin{array}{c}\text { Detection } \\
\text { method }\end{array}$ \\
\hline 1,2-Ethanediol, diformate & GC/MS \\
Acetic acid & GC/MS \& IC \\
Formic acid & IC \\
$\beta$-Hydroxybutyric acid & IC \\
Glycolic acid & IC \\
1,4-Dioxane-2,3-diol & Hypothesized \\
(2,3-dihydroxy-1,4-dioxane) & \\
[1,2-Ethanediylbis(oxy)]bis[methanol] & Hypothesized \\
\hline
\end{tabular}

DIOX reaction mechanisms. Applying the identified intermediates in the photocatalytic degradation of DIOX, a hypothetical pathway for its mineralization was proposed. The hypothetical reaction pathway for the photocatalytic degradation of DIOX is depicted in Figure 6. It is assumed that 1,4-dioxane is converted to hydroxylated 1,4-dioxane leading to ring opening. Organic acids are produced which ultimately convert to $\mathrm{CO}_{2}$ and water. Details of the reaction mechanisms and the kinetic model development for the photocatalytic destruction of DIOX is summarized in Appendix B. Dynamic model equations for the degradation of DIOX, developed in Appendix B, are shown in equations (B.17).

Kinetic parameter estimation for degradation of DIOX. In the next set of experiments, DIOX alone was examined in the slurry photoreactor. The kinetic parameters for the dynamic model equations (B.17) were estimated using the data obtained in different trials. The only significant and measurable intermediate in the photocatalytic destruction of DIOX was EDD. Due to the low concentrations of the other intermediates found during the photocatalytic degradation of DIOX, the reproducibility of the GC peak areas for these compounds was very poor. Therefore, for the purpose of modeling, these intermediates were not taken into account. Similar to THF rate equation, the term related to the other intermediates for DIOX was also neglected. The estimated parameter values at a $95 \%$ confidence level are listed in Table 6.
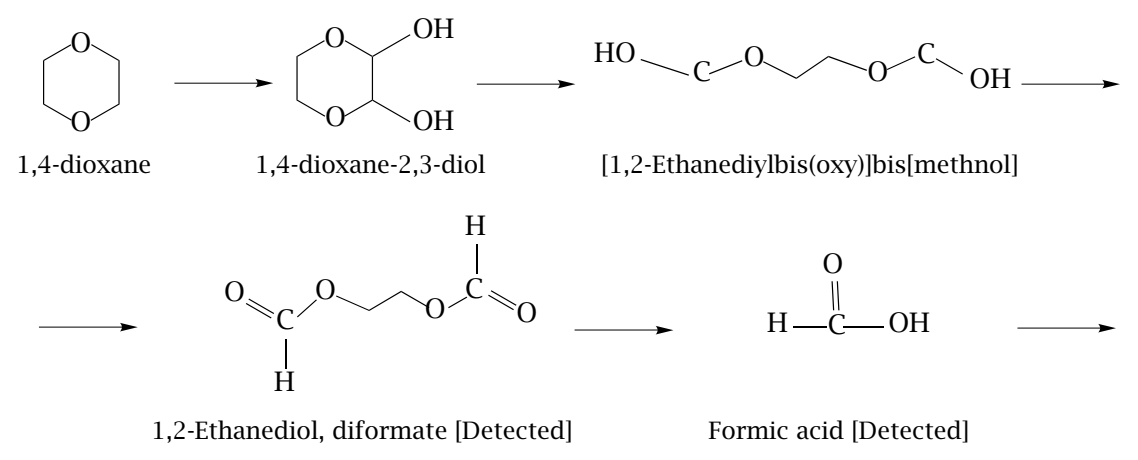

$\longrightarrow \quad \mathrm{CO}_{2}+\mathrm{H}_{2} \mathrm{O}$

Table 6. DIOX kinetic parameters in dynamic model equations (B.17).

\begin{tabular}{cc}
\hline Compound & $\begin{array}{c}\text { Parameters with 95\% } \\
\text { confidence levels }\end{array}$ \\
\hline \multirow{2}{*}{ DIOX } & $k_{\mathrm{DIOX}}=9.27 \pm 0.83\left[\mu \mathrm{Mmin}^{-1}\right]$ \\
& $K_{\mathrm{DIOX}}=(6.4 \pm 1.8) \times 10^{-3}\left[\mu \mathrm{M}^{-1}\right]$ \\
\hline \multirow{2}{*}{ EDD } & $k_{\mathrm{EDD}}=67.7 \pm 6.2\left[\mu \mathrm{M} \mathrm{min}^{-1}\right]$ \\
& $K_{\mathrm{EDD}}^{\prime}=1.10 \pm 0.21[]^{\mathrm{a}}$ \\
& $\left(\right.$ or $\left.K_{\mathrm{EDD}}=9.34 \times 10^{-4}\left[\mu \mathrm{M}^{-1}\right]\right)$ \\
& $\eta_{\mathrm{EDD}}=(1.18 \pm 0.12) \times 10^{3}[\mu \mathrm{M}]$ \\
\hline
\end{tabular}

a Designates dimensionless.

The LH model with no intermediate (equation (3)), was also applied to the experimental data. Table 7 depicts the estimated parameters for the photocatalytic degradation of DIOX in which no intermediates were considered. Figure 7 shows the comparison between the LH model with zero and one intermediate. The results showed that there is no significant change between these two models in all concentration ranges. Perhaps the concentration of EDD was so low during the photocatalytic degradation of DIOX that it did not affect the denominator of equations (B.17) to any significant extent. This suggests that EDD is not a kinetically limiting intermediate.

Table 7. DIOX kinetic parameters for the LH model in equation (3) without any intermediates.

\begin{tabular}{cc}
\hline Compound & Parameters with 95\% confidence levels \\
\hline \multirow{2}{*}{ DIOX } & $k_{\text {DIOX }}=7.26 \pm 0.60\left[\mu \mathrm{Mmin}^{-1}\right]$ \\
& $K_{\text {DIOX }}=(1.62 \pm 0.87) \times 10^{-2}\left[\mu \mathrm{M}^{-1}\right]$ \\
\hline
\end{tabular}




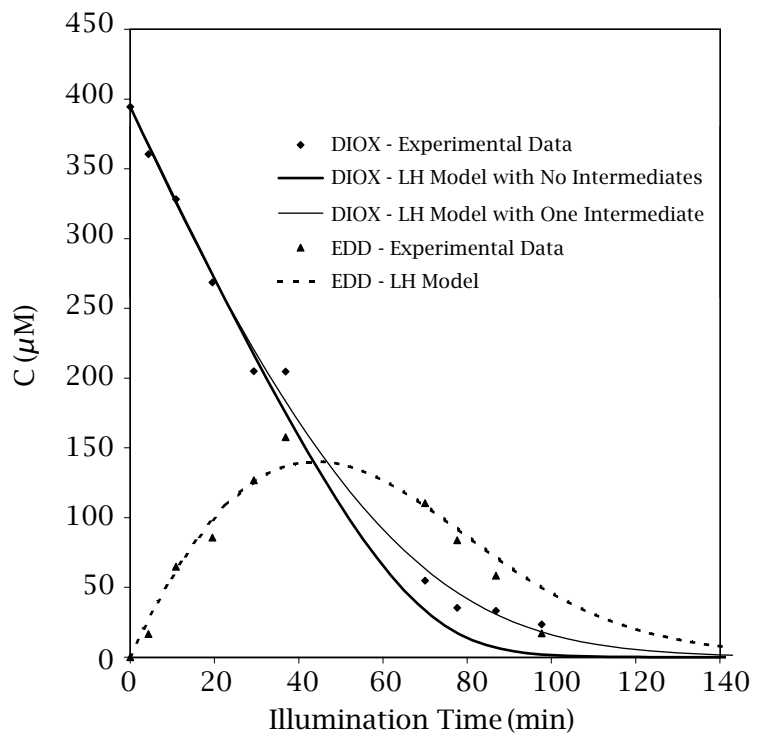

Figure 7. Comparison of the different models for the photocatalytic degradation of DIOX along with its intermediate, 1,2-ethanediol, diformate (EDD), in the slurry photoreactor; $C_{o, D I O X}=394.33 \mu \mathrm{M}$.

3.4. Binary system of THF and DIOX. The photocatalytic degradation of THF and DIOX as a binary system was studied. Based on the the significant and measurable intermediates for both THF and DIOX, the following dynamic model in equations (5) satisfactorily described the behavior of the binary system. The estimated kinetic parameters of the binary dynamic model in equations (5) are summarized in Table 8.

$$
\begin{aligned}
& -\frac{d[\mathrm{THF}]}{d t}=k_{\mathrm{app}}[\mathrm{THF}] \\
& +\frac{k_{\mathrm{THF}} K_{\mathrm{THF}}[\mathrm{THF}]}{1+K_{\mathrm{THF}}[\mathrm{THF}]+K_{\mathrm{GBL}}[\mathrm{GBL}]+K_{\mathrm{DIOX}}[\mathrm{DIOX}]}, \\
& \frac{d[\mathrm{GBL}]}{d t}=k_{\mathrm{app}}[\mathrm{THF}] \\
& -\frac{k_{\mathrm{GBL}} K_{\mathrm{GBL}}[\mathrm{GBL}]}{1+K_{\mathrm{THF}}[\mathrm{THF}]+K_{\mathrm{GBL}}[\mathrm{GBL}]+K_{\mathrm{DIOX}}[\mathrm{DIOX}]}, \\
& -\frac{d[\mathrm{DIOX}]}{d t}= \\
& \frac{k_{\mathrm{DIOX}} K_{\mathrm{DIOX}}[\mathrm{DIOX}]}{1+K_{\mathrm{THF}}[\mathrm{THF}]+K_{\mathrm{GBL}}[\mathrm{GBL}]+K_{\mathrm{DIOX}}[\mathrm{DIOX}]} .
\end{aligned}
$$

Table 8. Binary kinetic parameters in dynamic model (equations (5)).

\begin{tabular}{cc}
\hline Compound & $\begin{array}{c}\text { Parameters with 95\% } \\
\text { confidence levels }\end{array}$ \\
\hline \multirow{2}{*}{ THF } & $k_{\mathrm{app}}=(8.1 \pm 1.0) \times 10^{-3}\left[\mathrm{~min}^{-1}\right]$ \\
& $k_{\mathrm{THF}}=2.40 \pm 0.63\left[\mu \mathrm{Mmin}^{-1}\right]$ \\
& $K_{\mathrm{THF}}=(1.18 \pm 0.34) \times 10^{-2}\left[\mu \mathrm{M}^{-1}\right]$ \\
\hline \multirow{2}{*}{$\mathrm{GBL}$} & $k_{\mathrm{GBL}}=7.7 \pm 5.2\left[\mu \mathrm{Mmin}^{-1}\right]$ \\
& $K_{\mathrm{GBL}}=(1.8 \pm 1.0) \times 10^{-3}\left[\mu \mathrm{M}^{-1}\right]$ \\
\hline \multirow{2}{*}{$\mathrm{DIOX}$} & $k_{\mathrm{DIOX}}=5.4 \pm 3.5\left[\mu \mathrm{Mmin}^{-1}\right]$ \\
& $K_{\mathrm{DIOX}}=(5.4 \pm 3.9) \times 10^{-3}\left[\mu \mathrm{M}^{-1}\right]$ \\
\hline
\end{tabular}

Other models were also examined for the binary system. The LH model with no intermediate (equations (6)) was tested. The estimated parameters for this model are shown in Table 9.

$$
\begin{gathered}
-\frac{d[\mathrm{THF}]}{d t}=\frac{k_{\mathrm{THF}} K_{\mathrm{THF}}[\mathrm{THF}]}{1+K_{\mathrm{THF}}[\mathrm{THF}]+K_{\mathrm{DIOX}}[\mathrm{DIOX}]}, \\
-\frac{d[\mathrm{DIOX}]}{d t}=\frac{k_{\mathrm{DIOX}} K_{\mathrm{DIOX}}[\mathrm{DIOX}]}{1+K_{\mathrm{THF}}[\mathrm{THF}]+K_{\mathrm{DIOX}}[\mathrm{DIOX}]} .
\end{gathered}
$$

Table 9. Kinetic parameters in binary model equations (6); no intermediates were included in the model.

\begin{tabular}{cl}
\hline Compound & Parameters with 95\% confidence levels \\
\hline \multirow{2}{*}{ THF } & $k_{\mathrm{THF}}=12.7 \pm 1.4\left[\mu \mathrm{Mmin}^{-1}\right]$ \\
& $K_{\mathrm{THF}}=(8.9 \pm 2.3) \times 10^{-2}\left[\mu \mathrm{M}^{-1}\right]$ \\
\hline \multirow{2}{*}{ DIOX } & $k_{\mathrm{DIOX}}=2.87 \pm 0.21\left[\mu \mathrm{Mmin}^{-1}\right]$ \\
& $K_{\mathrm{DIOX}}=(1.36 \pm 0.22) \times 10^{-1}\left[\mu \mathrm{M}^{-1}\right]$ \\
\hline
\end{tabular}

In addition, the LH model considering one intermediate for THF was tested for the binary system (equations (7)) and the estimated parameters are shown in Table 10

$$
\begin{aligned}
& -\frac{d[\mathrm{THF}]}{d t}= \\
& \frac{k_{\mathrm{THF}} K_{\mathrm{THF}}[\mathrm{THF}]}{1+K_{\mathrm{THF}}[\mathrm{THF}]+K_{\mathrm{GBL}}[\mathrm{GBL}]+K_{\mathrm{DIOX}}[\mathrm{DIOX}]}, \\
& \frac{d[\mathrm{GBL}]}{d t}= \\
& \frac{k_{\mathrm{THF}} K_{\mathrm{THF}}[\mathrm{THF}]-k_{\mathrm{GBL}} K_{\mathrm{GBL}}[\mathrm{GBL}]}{1+K_{\mathrm{THF}}[\mathrm{THF}]+K_{\mathrm{GBL}}[\mathrm{GBL}]+K_{\mathrm{DIOX}}[\mathrm{DIOX}]}, \\
& -\frac{d[\mathrm{DIOX}]}{d t}= \\
& \frac{k_{\mathrm{DIOX}} K_{\mathrm{DIOX}}[\mathrm{DIOX}]}{1+K_{\mathrm{THF}}[\mathrm{THF}]+K_{\mathrm{GBL}}[\mathrm{GBL}]+K_{\mathrm{DIOX}}[\mathrm{DIOX}]} .
\end{aligned}
$$

Table 10. Binary kinetic parameters in LH model equations (7) considering one intermediate for THF.

\begin{tabular}{cl}
\hline Compound & Parameters with 95\% confidence levels \\
\hline \multirow{2}{*}{ THF } & $k_{\mathrm{THF}}=6.28 \pm 0.45\left[\mu \mathrm{Mmin}^{-1}\right]$ \\
& $K_{\mathrm{THF}}=(5.7 \pm 1.1) \times 10^{-3}\left[\mu \mathrm{M}^{-1}\right]$ \\
\hline \multirow{2}{*}{$\mathrm{GBL}$} & $k_{\mathrm{GBL}}=7.9 \pm 1.4\left[\mu \mathrm{Mmin}^{-1}\right]$ \\
& $K_{\mathrm{GBL}}=(5.0 \pm 1.0) \times 10^{-3}\left[\mu \mathrm{M}^{-1}\right]$ \\
\multirow{2}{*}{ DIOX } & $k_{\mathrm{DIOX}}=67 \pm 18\left[\mu \mathrm{Mmin}^{-1}\right]$ \\
& $K_{\mathrm{DIOX}}=(4.1 \pm 1.5) \times 10^{-4}\left[\mu \mathrm{M}^{-1}\right]$ \\
\hline
\end{tabular}

Figure 8 compares different models for the binary system. Both LH models with no intermediates or one intermediate overestimate the kinetic rates. This indicates that the dynamic model for the binary system needs at least one intermediate to satisfy the experimental data. Therefore, the modified LH model in which THF disappears via two routes, hydroxyl radical attack and oxidation to GBL, displays the best agreement with the experimental data. 


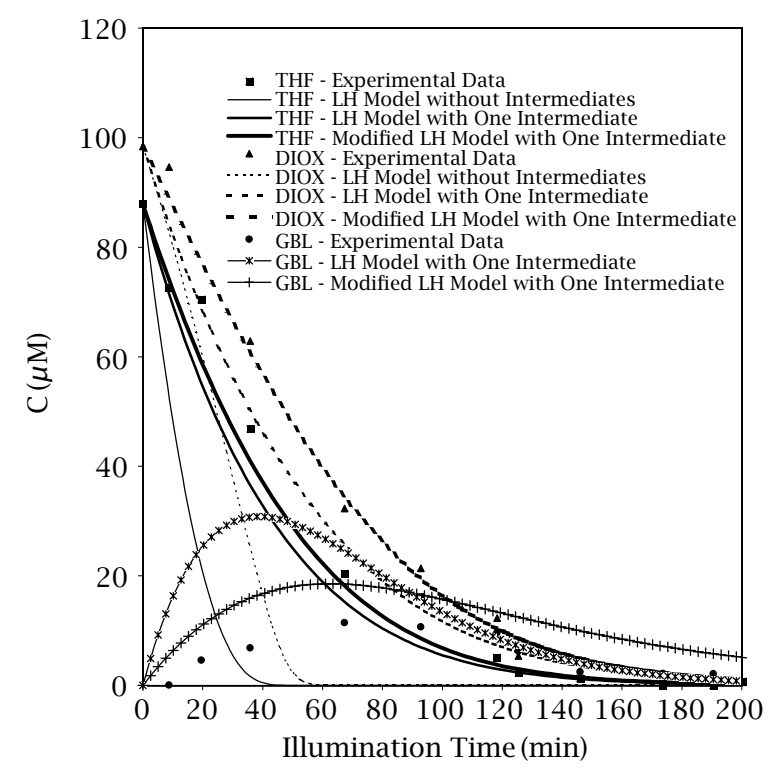

Figure 8. Comparison of the different models for the photocatalytic degradation of the mixture of THF and DIOX along with THF intermediate, $\gamma$-butyrolactone (GBL), in the slurry photoreactor; $C_{0, \mathrm{THF}}=87.9 \mu \mathrm{M}$ and $C_{0, \mathrm{DIOX}}=98.4 \mu \mathrm{M}$.

Figure 9 compares the photocatalytic degradation of THF in single and binary systems. Although the initial concentrations of THF and DIOX in the single component system were higher, their degradation rates were much faster in comparison to their degradation in the binary system. The decrease in the rate of the binary system was a result of competition for active sites between different species available in the system.

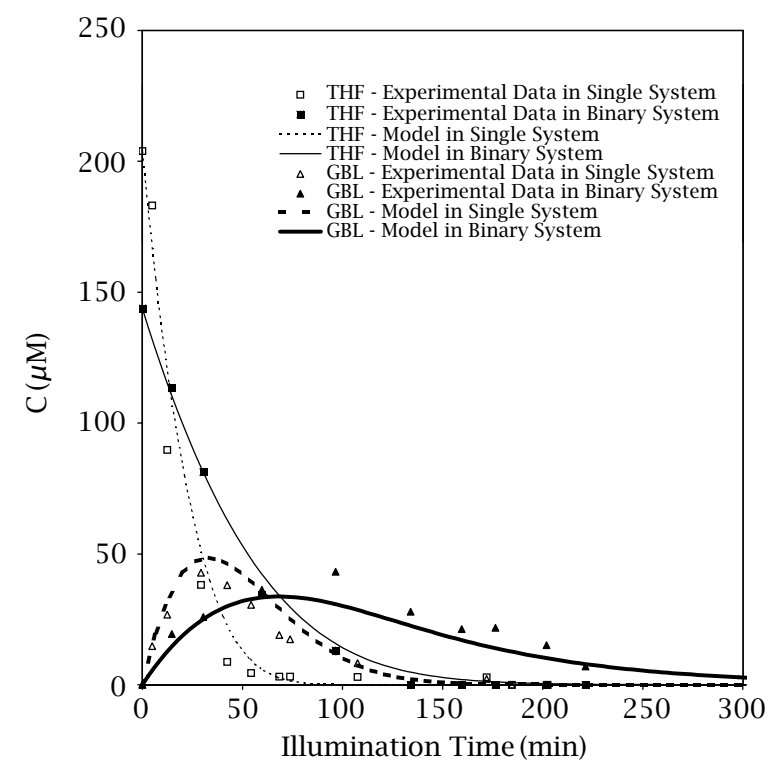

Figure 9. Comparison between single and binary systems for the photocatalytic degradation of THF in the slurry photoreactor; $C_{0, \mathrm{THF}}=203.96 \mu \mathrm{M}$ in single system and $C_{0, \mathrm{THF}}=143.81 \mu \mathrm{M}$ in binary system.

The kinetic parameters estimated in the single trials (see Tables 2 and 7) were applied to the binary dynamic model shown in equations (5). Figure 10 il- lustrates the results of the binary model with single system parameters. This figure indicates that the parameters in the single trials cannot be used in the binary system models simply because the degradation rates are not additive. Therefore, separate tests are needed in order to model a binary system.

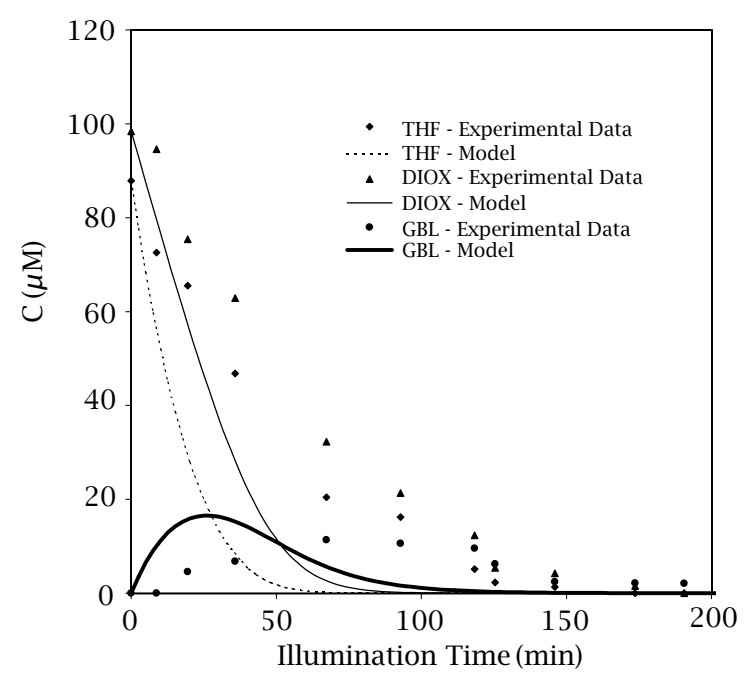

Figure 10. Binary model using kinetic parameters from single runs; $C_{0, \mathrm{THF}}=87.9 \mu \mathrm{M}$ and $C_{0, \mathrm{DIOX}}=98.4 \mu \mathrm{M}$.

\section{CONCLUSIONS}

Intermediates formed during the course of the photocatalytic degradation of THF and DIOX were experimentally identified using both GC/MS and IC methods. 2(3H)-Furanone, dihydro- ( $\gamma$-butyrolactone), succinic acid, acetic acid, formic acid, $\beta$-hydroxybutyric acid, and glycolic acid were identified as THF intermediates during its photocatalytic reaction. 2-Hydroxytetrahydrofuran, dihydro-5-hydroxy2(3H)-furanone, and 4-oxobutanoic acid were not detected but are believed to be THF intermediates, based on mechanistic considerations. Similarly, 1,2ethanediol, diformate, acetic acid, formic acid, $\beta$ hydroxybutyric acid, and glycolic acid were identified as intermediates of the photocatalytic degradation of DIOX. It is speculated that 1,4-dioxane-2,3diol (2,3-dihydroxy-1,4-dioxane) and [1,2-ethanediylbis(oxy)]bis[methanol] are also DIOX intermediates although they were not detected. Based on the detected and proposed intermediates, the hypothetical reaction mechanism pathways for both THF and DIOX were proposed, and kinetic models were developed. It was shown that the photocatalytic rate equation for THF and the binary systems followed a modified LH model. However, at higher concentrations of THF, the simple LH model was in a good agreement with the experimental data. It was also demonstrated that the photocatalytic degradation rates of THF and DIOX were slower in a binary system, and these rates could not be predicted based on single component experiments. 


\section{APPENDIX}

\section{A. DETAILS OF THF REACTION MECHANISMS}

Reactions (A.1) through (A.10) show the summary of the general reactions occurring in all photocatalysis processes [13].

$$
\begin{aligned}
& \text { Excitation } \\
& \mathrm{TiO}_{2} \stackrel{h v}{\longrightarrow} e^{-}+h^{+}
\end{aligned}
$$

\section{Adsorption}

$$
\begin{aligned}
& \mathrm{O}_{\mathrm{L}}^{2-}+\mathrm{Ti}^{\mathrm{IV}}+\mathrm{H}_{2} \mathrm{O} \rightleftharpoons \mathrm{O}_{\mathrm{L}} \mathrm{H}^{-}+\mathrm{Ti}^{\mathrm{IV}}-\mathrm{OH}^{-} \\
& \mathrm{Ti}^{\mathrm{IV}}+\mathrm{H}_{2} \mathrm{O} \rightleftharpoons \mathrm{Ti}^{\mathrm{IV}}-\mathrm{H}_{2} \mathrm{O} \\
& R_{i}+\mathrm{Site} \rightleftharpoons R_{i, \text { ads }} \\
& \mathrm{Ti}^{\mathrm{IV}}+\cdot \mathrm{OH} \rightleftharpoons \mathrm{Ti}^{\mathrm{IV}} \imath \cdot \mathrm{OH}
\end{aligned}
$$

\section{Recombination}

$$
e^{-}+h^{+} \rightarrow \text { heat }
$$

\section{Trapping}

$$
\begin{aligned}
& \mathrm{Ti}^{\mathrm{IV}}-\mathrm{OH}^{-}+h^{+} \rightleftharpoons \mathrm{Ti}^{\mathrm{IV}} \curlywedge \bullet \mathrm{OH} \\
& \mathrm{Ti}^{\mathrm{IV}}-\mathrm{H}_{2} \mathrm{O}+h^{+} \rightleftharpoons \mathrm{Ti}^{\mathrm{IV}} \curlywedge \cdot \mathrm{OH}+H^{+} \\
& \mathrm{Ti}^{\mathrm{IV}}+e^{-} \rightleftharpoons \mathrm{Ti}^{\mathrm{III}} \\
& \mathrm{Ti}^{\mathrm{III}}+\mathrm{O}_{2} \rightleftharpoons \mathrm{Ti}^{\mathrm{IV}}-\mathrm{O}_{2}^{\bullet-}
\end{aligned}
$$

Potential reaction mechanisms for the degradation of THF are shown in reactions (A.11) through (A.25). Since reaction mechanisms in photocatalysis are very complicated, each proposed reaction mechanism may be involved in different intermediate pathways. As a result, only the global reaction mechanism in each step is considered. For example, the production of $\gamma$ butyrolactone (GBL) may have several extra steps as shown in Figure 11.

After adsorption of THF onto the catalyst surface (reaction (A.11)), it is oxygenated through an adsorbed oxygen, $\mathrm{Ti}^{\mathrm{IV}}-\mathrm{O}_{2}^{\cdot-}$, as shown in reaction ((A.12.) During this reaction, $\gamma$-butyrolactone is produced as the most significant and measurable intermediate. Adsorbed GBL, in turn, must reversibly desorb and migrate into the bulk phase (reaction (A.13)). The detection and, therefore, the measurement of GBL is possible due to its desorption into the liquid bulk phase. Since plentiful hydroxyl radicals are produced during the process, most probably all organic species get attacked by hydroxyl radicals either on the surface of the photocatalyst or in the liquid bulk phase. Hence, adsorbed GBL can react with - OH toproduce 5-hydroxy-2(3H)furanone, dihydro- (reactions (A.14) through (A.17)). Alternatively, hydroxyl radicals can attack THF resulting in the formation of 2-hydroxytetrahydrofuran although this species was not detected in this study. Dihydro-5-hydroxy-2(3H)furanone may also be produced through oxygenation of 2-hydroxytetrahydrofuran as shown in reaction (A.19). This intermediate can also desorb into the liquid phase.
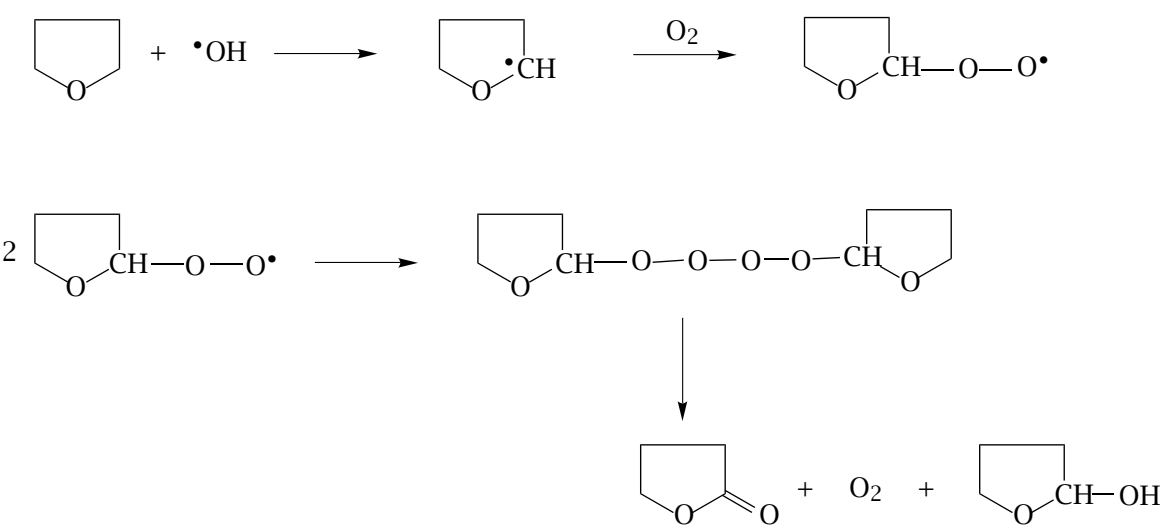

Figure 11. Details of the THF oxidation by hydroxyl radical attack.

Dihydro-5-hydroxy-2(3H)-furanone is unstable leading to ring opening to produce 4-oxobutanoic acid as another intermediate (reaction (A.21)). 4-Oxobutanoic acid is attacked by another hydroxyl radical resulting in the formation of succinic acid. This organic acid was detected in the samples by GC/MS. Succinic acid may desorb into the bulk phase and convert to formic acid (reactions (A.23) and (A.24)). The general reaction in which succinic acid breaks down into smaller $\mathrm{C}$ fragments is depicted in reaction (A.25).

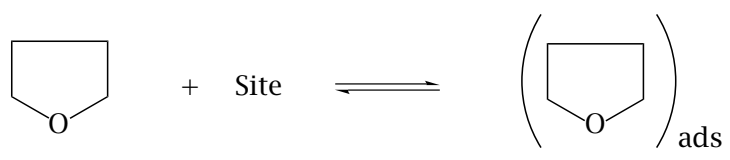




$$
\left(\square_{\mathrm{O}}\right)_{\mathrm{ads}}+\mathrm{Ti}^{\mathrm{IV}}-\mathrm{O}_{2}^{--} \rightleftharpoons(\underbrace{}_{\mathrm{O}})_{\mathrm{ads}}+\mathrm{Ti}^{\mathrm{III}}-\mathrm{H}_{2} \mathrm{O}
$$<smiles>C=CCCCCCCCCCOC(=O)CCC</smiles><smiles>CC(C)C1CCC(=O)O1</smiles>

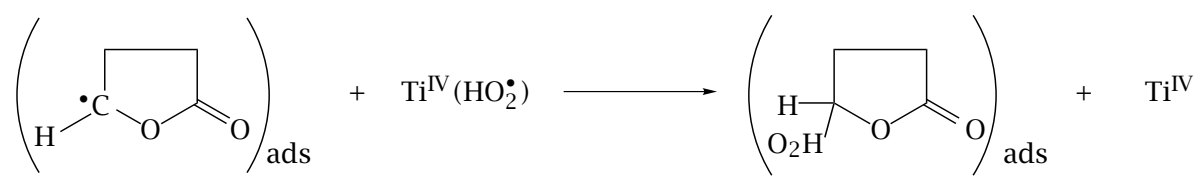

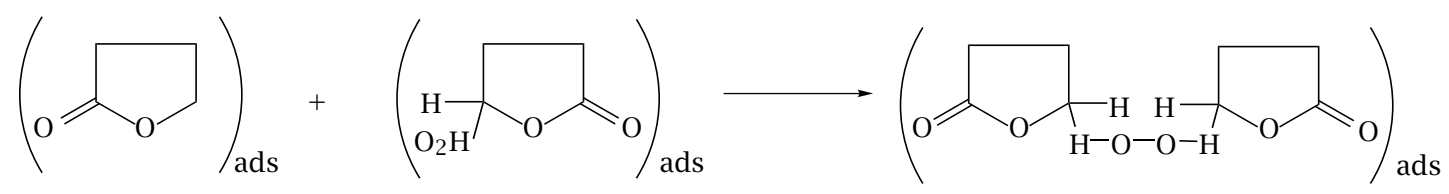<smiles>CC(C)C1CCC(=O)O1</smiles>

$$
\left(\mathrm{O}_{\mathrm{O}}\right)_{\mathrm{ads}}+\cdot \mathrm{OH} \longrightarrow\left(\mathrm{O}_{\mathrm{OH}}\right)_{\mathrm{ads}}
$$

$$
\left(\mathrm{O}_{\mathrm{OH}}\right)_{\mathrm{ads}}+\mathrm{Ti}^{\mathrm{IV}}-\mathrm{O}_{2}^{--} \longrightarrow\left(\mathrm{OH}_{\mathrm{O}}\right)_{\mathrm{ads}}+\mathrm{Ti}^{\mathrm{III}}-\mathrm{H}_{2} \mathrm{O}
$$




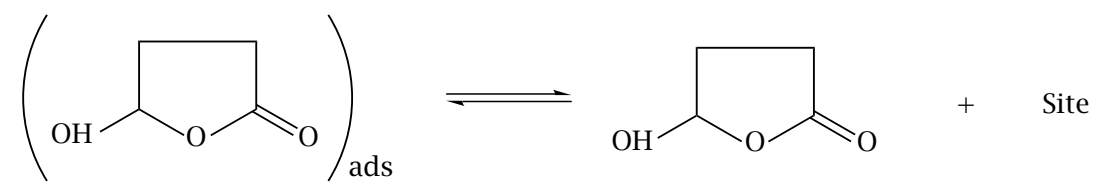

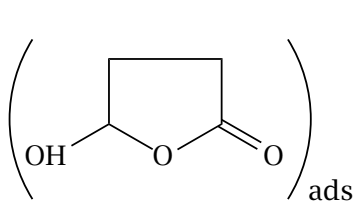<smiles>O=C(O)CCC(=O)O</smiles>

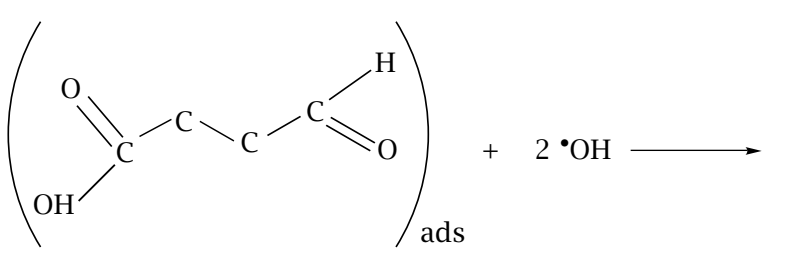<smiles>O=C(O)CCC(=O)O</smiles><smiles>O=C(O)CCC(=O)O</smiles><smiles>C=CCCCCC(=O)O</smiles><smiles>O=C(O)CCC(=O)O</smiles><smiles>CC(C)C(=O)O</smiles><smiles>CS[C@H](C[C@H](C)C(=O)OCC(=O)O)C(=O)O</smiles>

A.1. THF rate equations. Based on the reaction mechanisms proposed in the previous section, the rate equations for the photocatalytic degradation of THF in water were developed. From reactions (A.12) and (A.18), the rate of the disappearance of adsorbed THF may be written as:

$$
\begin{aligned}
-\frac{d[\mathrm{THF}]_{\mathrm{ads}}}{d t}= & k_{A .12+} a_{s}[\mathrm{THF}]_{\mathrm{ads}}\left[\mathrm{Ti}^{\mathrm{IV}}-\mathrm{O}_{2}^{--}\right] \\
& +k_{A .18} a_{s}\left[{ }^{\bullet} \mathrm{OH}\right][\mathrm{THF}]_{\mathrm{ads}} .
\end{aligned}
$$

Assuming that reactions (A.9), (A.10), and (A.11) quickly approach equilibrium, the following equations can be derived:

$$
\begin{gathered}
{\left[\mathrm{Ti}^{\mathrm{III}}\right]=K_{A .9}\left[\mathrm{Ti}^{\mathrm{IV}}\right]\left[e^{-}\right],} \\
{\left[\mathrm{Ti}^{\mathrm{IV}}-\mathrm{O}_{2}^{\bullet-}\right]=K_{A .10}\left[\mathrm{Ti}^{\mathrm{III}}\right]\left[\mathrm{O}_{2}\right],} \\
{[\mathrm{THF}]_{\text {ads }}=K_{A .11}[\text { Site }][\mathrm{THF}] .}
\end{gathered}
$$

By substituting equation (A.27) into equation (A.28) and considering that $\left[e^{-}\right]=\left[h^{+}\right]$, the concentration of the titanium dioxide radical, $\left[\mathrm{Ti}^{\mathrm{IV}}-\mathrm{O}_{2}^{--}\right]$, is simplified as follows:

$$
\left[\mathrm{Ti}^{\mathrm{IV}}-\mathrm{O}_{2}^{\bullet-}\right]=K_{A .9} K_{A .10}\left[\mathrm{Ti}^{\mathrm{IV}}\right]\left[h^{+}\right]\left[\mathrm{O}_{2}\right]
$$

By combining equations (A.26), (A.29), and (A.30), the following reaction rate for THF may be derived.

$$
\begin{aligned}
-\frac{d[\mathrm{THF}]}{d t}= & \frac{k_{A .12+} K_{A .9} K_{A .10} a_{s}}{K_{A .11}[\mathrm{Site}]}\left[\mathrm{Ti}^{\mathrm{IV}}\right]\left[h^{+}\right]\left[\mathrm{O}_{2}\right][\mathrm{THF}]_{\mathrm{ads}} \\
& +\frac{k_{A .18} a_{s}}{K_{A .11}[\text { Site }]}\left[{ }^{\circ} \mathrm{OH}\right][\mathrm{THF}]_{\text {ads }} .
\end{aligned}
$$

The $\mathrm{pH}$ throughout all experimental runs was monitored and found to be $4 \pm 0.5$. The $\mathrm{pH}$ did not change significantly during any experiments. Considering the low $\mathrm{pH}$ range for the runs, reaction (A.8) is more likely 
to proceed than reaction (A.7) under these conditions. Using this assumption and by applying the steady state approximation for the ${ }^{\bullet} \mathrm{OH}$ concentration at low $\mathrm{pH}$, the following rate equation can be derived:

$$
\begin{aligned}
\frac{d[\cdot \mathrm{OH}]}{d t}= & \alpha k_{A .8+}\left[\mathrm{Ti}^{\mathrm{IV}}-\mathrm{H}_{2} \mathrm{O}\right]\left[h^{+}\right] a_{s} \\
& -k_{A .8-} a_{s}\left[\mathrm{Ti}^{\mathrm{IV}} \imath^{\bullet} \mathrm{OH}\right]\left[H^{+}\right] \\
& -k_{A .18} a_{s}\left[\bullet^{\bullet} \mathrm{OH}\right][\mathrm{THF}]_{\mathrm{ads}} \\
& -k_{A .14} a_{s}\left[\bullet^{\bullet} \mathrm{OH}\right][\mathrm{GBL}]_{\mathrm{ads}} \\
& -\sum_{j=3}^{n} k_{j}\left[\bullet^{\circ} \mathrm{OH}\right]\left[R_{j, \text { ads }}\right] a_{s} \approx 0,
\end{aligned}
$$

where $j=$ the other components which are attacked by hydroxyl radicals; in this case $j \neq$ THF \& GBL;

$n=$ the total number of different organic species present in the system;

$\alpha=$ the proportionality constant;

$\left[H^{+}\right]=10^{-\mathrm{pH}}$

$a_{s}=$ particle surface area, $\left[\mathrm{m}^{2}\right]$.

GC analyses revealed that the concentrations of certain intermediates were either not measurable or present at very low concentration levels. Hence, the last term in equation (A.32), which is related to the other intermediates with relatively low concentrations, is assumed to be negligible. As shown by other researchers $[12,13]$, hole trapping is the most probable source of hydroxyl radical generation. Therefore, reactions (A.8+) and (A.5-) together are the possible mechanisms for producing hydroxyl radicals, where + and - refer to the forward and backward reactions. reaction (A.5) is used to determine the adsorption constant as follows:

$$
\left[\mathrm{Ti}^{\mathrm{IV}}, \bullet \mathrm{OH}\right]=K_{A .5}\left[\mathrm{Ti}^{\mathrm{IV}}\right]\left[\bullet^{\bullet} \mathrm{OH}\right] .
$$

As $\mathrm{pH}$ does not fluctuate during the course of the reaction, $\left[\mathrm{H}^{+}\right]$can be assumed to be constant. The $\left[\mathrm{Ti}^{\mathrm{IV}}-\mathrm{H}_{2} \mathrm{O}\right]$ is the surface concentration of bound $\mathrm{H}_{2} \mathrm{O}$ at low $\mathrm{pH}$ and is assumed to remain relatively constant. By considering these assumptions and substituting equation (A.33) into equation (A.32), the expression for the hydroxyl radical concentration is:

$$
\left[{ }^{\bullet} \mathrm{OH}\right]=\frac{\alpha k_{A .8+}^{\prime}\left[h^{+}\right]}{k_{A .8-}^{\prime} K_{A .5}\left[\mathrm{Ti}^{\mathrm{IV}}\right]+k_{A .18}[\mathrm{THF}]_{\mathrm{ads}}+k_{A .14}[\mathrm{GBL}]_{\mathrm{ads}}},
$$

where $k_{A .8-}^{\prime}=k_{A .8-} 10^{-\mathrm{pH}}$;

$$
k_{A .8+}^{\prime}=k_{A .8+}\left[\mathrm{Ti}^{\mathrm{IV}}-\mathrm{H}_{2} \mathrm{O}\right] .
$$

Similarly, using the steady state approximation, the hole concentration, $\left[h^{+}\right]$, at high photon flux is:

$$
\left[h^{+}\right]=\left(\frac{k_{A .1} I a_{c}}{k_{A .6} v_{p}}\right)^{1 / 2},
$$

where $I=$ Molar photon flux, [Einstein $\mathrm{m}^{-2} \mathrm{~s}^{-1}$ ];

$$
v_{p}=\text { Particle volume, }\left[\mathrm{m}^{3}\right] ;
$$

$a_{c}=$ Titanium dioxide particle area normal to illumination, $\left[\mathrm{m}^{2}\right]$.

The kinetic rate equation for GBL can be written as follows:

$$
\begin{aligned}
\frac{d[\mathrm{GBL}]}{d t}= & k_{A .12+} a_{s}[\mathrm{THF}]_{\mathrm{ads}}\left[\mathrm{Ti}^{\mathrm{IV}}-\mathrm{O}_{2}^{\cdot-}\right] \\
& -k_{A .14} a_{s}\left[{ }^{\bullet} \mathrm{OH}\right][\mathrm{GBL}]_{\mathrm{ads}} .
\end{aligned}
$$

By substituting equations (A.34) and (A.35) into equations (A.31) and (A.36), the final dynamic model for THF, considering GBL as its major kinetic intermediate, may be written as follows:

$$
\begin{gathered}
-\frac{d[\mathrm{THF}]}{d t}=k_{\mathrm{app}}[\mathrm{THF}]+\frac{k_{\mathrm{THF}} K_{\mathrm{THF}}[\mathrm{THF}]}{1+K_{\mathrm{THF}}[\mathrm{THF}]+K_{\mathrm{GBL}}[\mathrm{GBL}]}, \\
\frac{d[\mathrm{GBL}]}{d t}=k_{\mathrm{app}}[\mathrm{THF}]-\frac{k_{\mathrm{GBL}} K_{\mathrm{GBL}}[\mathrm{GBL}]}{1+K_{\mathrm{THF}}[\mathrm{THF}]+K_{\mathrm{GBL}}[\mathrm{GBL}]},
\end{gathered}
$$

where:

$$
\begin{aligned}
k_{\mathrm{app}} & =k_{A .12+} K_{A .9} K_{A .10} a_{s}\left[\mathrm{Ti}^{\mathrm{IV}}\right]\left[\mathrm{O}_{2}\right]\left(\frac{k_{A .1} I a_{c}}{k_{A .6} v_{p}}\right)^{1 / 2} \\
k_{\mathrm{THF}} & =\frac{\alpha k_{A .8+}^{\prime} a_{s}\left(k_{A .1} I a_{c} / k_{A .6} v_{p}\right)^{1 / 2}}{K_{A .11}[\mathrm{Site}]} \\
k_{\mathrm{GBL}} & =\alpha k_{A .8+}^{\prime} a_{s}\left(\frac{k_{A .1} I a_{c}}{k_{A .6} v_{p}}\right)^{1 / 2} \\
K_{\mathrm{THF}} & =\frac{k_{A .18} K_{A .11}[\mathrm{Site}]}{k_{A .8-}^{\prime} K_{A .5}\left[\mathrm{Ti}^{\mathrm{IV}}\right]} \\
K_{\mathrm{GBL}} & =\frac{k_{A .14}[\mathrm{Site}]}{k_{A .8-}^{\prime} K_{A .5} K_{A .13}\left[\mathrm{Ti}^{\mathrm{IV}}\right]}
\end{aligned}
$$

Equations (A.37) together present a simplified dynamic model of the rate equations for the photocatalytic degradation of THF in water. These two equations must be solved simultaneously in order to estimate the kinetic parameters. In comparison to the $\mathrm{LH}$ model described in equation (1), it can be seen that equations (A.37) have one extra term. Although the model is LH, a first order term for THF has been obtained in the derivation of these equations, accounting for the oxygenation of THF through adsorbed oxygen to produce GBL. This means that the disappearance of THF is either a consequence of the attack by hydroxyl radicals (reaction (A.18)) or due to oxidation of THF by adsorbed oxygen (reaction (A.12)).

\section{B. DETAILS OF DIOX REACTION MECHANISMS}

DIOX adsorbs onto the surface of the photocatalyst as shown in reaction (B.1). Hydroxyl radicals attack DIOX producing the intermediate, 1,4-dioxane-2,3-diol (reaction (B.2)). This intermediate was not detected in the analyses. There is a possibility that some intermediates are tightly bound to the photocatalyst or their concentration in the solution are below the extraction limit of SPME. Also, the intrinsic reaction rate constants for some of the intermediates might be too high such that their detection was impossible. Alternatively, as shown in reaction (B.3), the 1,4-dioxane-2,3-diol ring may open 
to produce the intermediate, 1,2-ethanediol, diformate (reaction (B.4)), which was detected by GC/MS. Then, EDD either desorbs into the bulk phase or is converted to formic acid (reactions (B.5) and (B.6)). It is also possi- ble that hydroxyl radicals attack EDD thereby converting it to smaller $C$ fragments. These smaller $C$ fragments eventually lead to the final product of photocatalysis, $\mathrm{CO}_{2}$, as revealed in reaction (B.7).

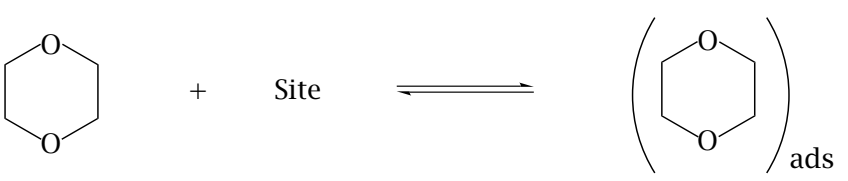<smiles>CC1(O)OCCOC1O</smiles><smiles>CCCCCC(C)C(C)OCOCOCC</smiles><smiles>CC(C)C(C)C(=O)OCCOC(=O)O</smiles><smiles>CCCCCCCC(=O)OCCOC(=O)C=O</smiles><smiles>CC(C)C(=O)OCCOC(=O)C(C)C</smiles>

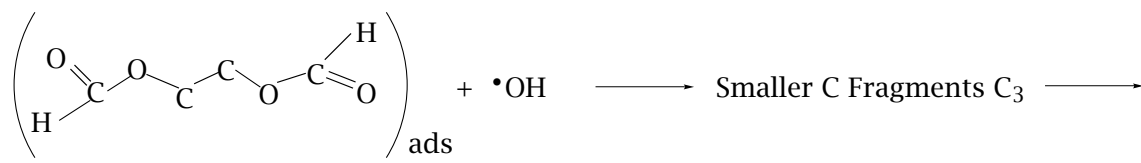

B.1. DIOX rate equations. The dynamic model for the photocatalytic degradation of DIOX in water was developed using a similar approach to that taken for THF. DIOX disappearance due to the hydroxyl radical attack leads to:

$$
-\frac{d[\mathrm{DIOX}]_{\mathrm{ads}}}{d t}=k_{B .2} a_{s}\left[{ }^{\bullet} \mathrm{OH}\right][\mathrm{DIOX}]_{\mathrm{ads}} .
$$

Assuming the concentrations of all other intermedi- 
ates, except EDD, are negligible the concentration of the hydroxyl radicals is:

$$
\begin{aligned}
& {\left[{ }^{\bullet} \mathrm{OH}\right]=} \\
& \frac{\alpha k_{A .8+}^{\prime}\left[h^{+}\right]}{k_{A .8-}^{\prime} K_{A .5}\left[\mathrm{Ti}^{\mathrm{IV}}\right]+k_{B .2}[\mathrm{DIOX}]_{\mathrm{ads}}+k_{\mathrm{EDD},} \cdot \mathrm{OH}[\mathrm{EDD}]_{\mathrm{ads}}},
\end{aligned}
$$

where $k_{A .8-}^{\prime}=k_{A .8-} 10^{-\mathrm{pH}}$;

$$
k_{A .8+}^{\prime}=k_{A .8+}\left[\mathrm{Ti}^{\mathrm{IV}}-\mathrm{H}_{2} \mathrm{O}\right]
$$

$k_{\mathrm{EDD}, \cdot \mathrm{OH}}=$ rate constant in reaction EDD with ${ }^{\bullet} \mathrm{OH}$.

Assuming that reaction (B.1) is in equilibrium, we have:

$$
[\mathrm{DIOX}]_{\mathrm{ads}}=K_{B .1}[\text { Site }][\mathrm{DIOX}] \text {. }
$$

By writing a similar rate equation for EDD and substituting equations (B.9) and (B.10) into equation (B.8), the dynamic model for the photocatalytic degradation of DIOX is:

$$
\begin{aligned}
-\frac{d[\mathrm{DIOX}]}{d t} & =\frac{k_{\mathrm{DIOX}} K_{\mathrm{DIOX}}[\mathrm{DIOX}]}{1+K_{\mathrm{DIOX}}[\mathrm{DIOX}]+K_{\mathrm{EDD}}[\mathrm{EDD}]}, \\
\frac{d[\mathrm{EDD}]}{d t} & =\frac{k_{\mathrm{DIOX}} K_{\mathrm{DIOX}}[\mathrm{DIOX}]-k_{\mathrm{EDD}} K_{\mathrm{EDD}}[\mathrm{EDD}]}{1+K_{\mathrm{DIOX}}[\mathrm{DIOX}]+K_{\mathrm{EDD}}[\mathrm{EDD}]}
\end{aligned}
$$

in which:

$$
\begin{aligned}
k_{\mathrm{DIOX}} & =\frac{\alpha k_{A .8+}^{\prime} a_{s}\left(k_{A .1} I a_{c} / k_{A .6} v_{p}\right)^{1 / 2}}{K_{B .1}[\mathrm{Site}]}, \\
k_{\mathrm{EDD}} & =\frac{\alpha k_{A .8+}^{\prime} a_{s}\left(k_{A .1} I a_{c} / k_{A .6} v_{p}\right)^{1 / 2}}{K_{\mathrm{EDD}, \mathrm{ads}}[\mathrm{Site}]}, \\
K_{\mathrm{DIOX}} & =\frac{k_{B .2} K_{B .1}[\mathrm{Site}]}{k_{A .8-}^{\prime} K_{A .5}\left[\mathrm{Ti}^{\mathrm{IV}}\right]}, \\
K_{\mathrm{EDD}} & =\frac{k_{\mathrm{EDD}, \cdot \mathrm{OH}} K_{\mathrm{EDD}, \mathrm{ads}}[\mathrm{Site}]}{k_{A .8-}^{\prime} K_{A .5}\left[\mathrm{Ti}^{\mathrm{IV}}\right]}
\end{aligned}
$$

and $K_{\mathrm{EDD} \text {,ads }}$ is the $E D D$ binding constant.

It is obvious from equations (B.11) that DIOX degradation follows the LH form, and unlike THF, it does not include an extra term in its dynamic model. As mentioned earlier, this is due to the hypothesis that DIOX disappears only through hydroxyl radical attack. Since EDD was unavailable to calibrate the GC, its concentration may be expressed in terms of a GC peak area ratio which was experimentally measured during the trials. Hence:

$$
\text { [EDD }]=\eta_{\mathrm{EDD}} A_{r, \mathrm{EDD}},
$$

where $\eta_{\mathrm{EDD}}=$ calibration constant for EDD;

$$
A_{r, \mathrm{EDD}}=\mathrm{GC} \text { peak area ratio for EDD. }
$$

By substituting equation (B.16) into equation (B.11), the dynamic model for DIOX can be obtained as follows:

$$
\begin{aligned}
& -\frac{d[\mathrm{DIOX}]}{d t}=\frac{k_{\mathrm{DIOX}} K_{\mathrm{DIOX}}[\mathrm{DIOX}]}{1+K_{\mathrm{DIOX}}[\mathrm{DIOX}]+K_{\mathrm{EDD}}^{\prime} A_{r, \mathrm{EDD}}}, \\
& \frac{d A_{r, \mathrm{EDD}}}{d t}= \\
& \left(\frac{1}{\eta_{\mathrm{EDD}}}\right) \frac{k_{\mathrm{DIOX}} K_{\mathrm{DIOX}}[\mathrm{DIOX}]-k_{\mathrm{EDD}} K_{\mathrm{EDD}}^{\prime} A_{r, \mathrm{EDD}}}{1+K_{\mathrm{DIOX}}[\mathrm{DIOX}]+K_{\mathrm{EDD}}^{\prime} A_{r, \mathrm{EDD}}}
\end{aligned}
$$

in which:

$$
K_{\mathrm{EDD}}^{\prime}=\eta_{\mathrm{EDD}} K_{\mathrm{EDD}}
$$

\section{ACKNOWLEDGEMENTS}

The support of the Natural Sciences and Engineering Research Council of Canada is gratefully acknowledged.

\section{REFERENCES}

[1] M. A. Fox, Photocatalytic oxidation of organic substrates, M. Schiavello (ed.), Kluwer Academic Publishers, Dordrecht, The Netherlands, 1988, p. 445.

[2] M. Anne Fox and M. T. Dulay, Chem. Rev. 93 (1993), 341.

[3] N. Getoff, Electron Beam Remediation of Water. A Short Review, The First International Conference on Advanced Oxidation Technology for Water and Air Remediation (London Convention Center, London, Ontario, Canada), June 25-30, 1994, p. 128.

[4] M. Grätzel, Heterogeneous Photochemical Electron Transfer, CRC Press, Inc., 1989.

[5] M. Hoffmann, S. T. Martin, W. Choi, and D. W. Bahnemann, Chemical Reviews 95(1) (1995), 69.

[6] A. L. Linsebigler, G. Lu, and John T. Yates, Jr., Chemical Review 95(3) (1995), 735.

[7] R. W. Matthews, Environmental Photochemical and Photocatalytic Processes. Degradation of Organic Compounds, E. Pelizzetti and M. Schiavello (eds.), Kluwer Academic Publishers, Dordrecht, The Netherlands, 1991, p. 427.

[8] D. F. Ollis, Environ. Sci. Technol. 19(6) (1985), 480.

[9] M. Schiavello (ed.), Photoelectrochemistry, Photocatalysis, and Photoreactors : Fundamental and Developments, series NATO, Dordrecht, 1985.

[10] E. R. Carraway, A. J. Hoffmanm, and M. R. Hoffmann, Environ. Sci. Technol. 28(5) (1994), 786.

[11] Y. Mao, C. Schöneich, and K.-D. Asmus, J. Phys. Chem. 95(24) (1991), 10080

[12] C. S. Turchi and D. F. Ollis, J. Catal. 122 (1990), 178

[13] C. S. Turchi, Heterogeneous Photocatalytic Degradation of Organic Water Contaminants: Kinetics and Hydroxyl Radical Mechanisms, Ph.D. thesis, North Carolina State University, Raleigh, North Carolina, USA, 1990.

[14] H. Al-Ekabi, N. Serpone, E. Pelizzetti, C. Minero, M. A. Fox, and R. B. Draper, Langmuir 5(1) (1989), 250.

[15] C. G. Hill, An Introduction to Chemical Engineering Kinetics and Reactor Design, Wiley, New York, 1977.

[16] R. W. Matthews, J. Catal. 111 (1988), 264.

[17] K.-I. Okamoto, Y. Yamamoto, H. Tanaka, M. Tanaka, and A. Itaya, Bull. Chem. Soc. Jpn. 58(7) (1985), 2015.

[18] C. S. Turchi and D. F. Ollis, J. Catal. 119 (1989), 483.

[19] D. F. Ollis, E. Pelizzetti, and N. Serpone, Photocatalysis, Fundamental and Applications, N. Serpone and E. Pellizzetti (eds.) John Wiley and Sons, New York, 1989, p. 603. 
[20] S. Budvari (ed.), The Merck Index, 11th ed., Merck and Co., Rahway, NJ, 1989.

[21] R. Hartung, Health and Environmental Effects Assessment for 1,4-Dioxane, Gelman Sciences, Ann Arbor, MI, 1989.

[22] J. M. Smith, Grant and Hackh's Chemical Dictionary, McGraw-Hill, New York, 1987.

[23] F. D. Snell and L. S. Ettre (eds.), Encyclopedia of Industrial Chemical Analysis, Wiley, New York, N.Y., USA, 1971.

[24] H. A. Painter and E. F. King, Assessment of Biodegradability of Chemicals in Water by Manometric Respirometry, Ring Test Program 1987-84 (Comm Eur Communities (Rep.), EUR, EUR 9962), 1985, pp. CA 103, 183-290.

[25] D. Bernhardt and H. Diekmann, Appl. Microbiol. Biotechnol. 36 (1991), 120.
[26] P. H. Howard, R. S. Boethling, W. F. Jarvis, W. M. Meylan, and E. M. Michalenko (eds.), Handbook of Environmental Degradation Rates, Lewis Publishers Inc., Chelsea, Michigan, 1991.

[27] M. Kawasaki, Ecotox. Environ. Safety 4 (1980), 444.

[28] S. Sasaki, Aquatic Pollutants: Transformation and Biological Effects, O. Hutzinger et al. (ed.), Pergamon Press, Oxford, U.K., 1978, p. 283.

[29] S. Peldszus, P. M. Huck, and S. A. Andrews, Journal of Chromatography A 723 (1996), 27.

[30] M. Mehrvar, W. A. Anderson, M. Moo-Young, and P. M. Reilly, Chem. Eng. Sci. 55(21) (2000), 4885.

[31] R. R. Hill, G. E. Jeff, and D. R. Roberts, J. Photochem. Photobiol. A: Chem. 108 (1997), 55.

[32] V. Maurino, P. Calza, C. Minero, E. Pelizzetti, and M. Vincenti, Chemosphere 35(11) (1997), 2675. 


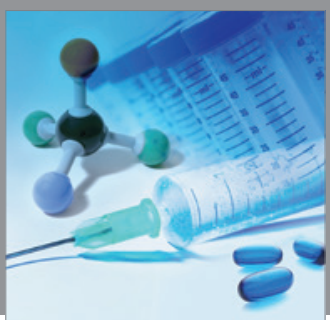

International Journal of

Medicinal Chemistry

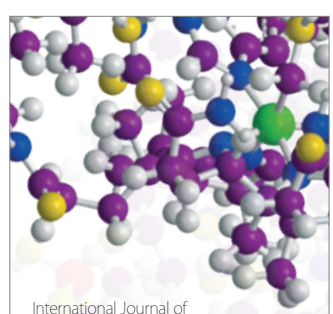

Carbohydrate Chemistry

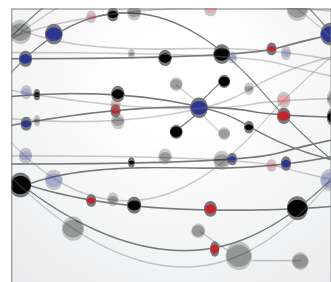

The Scientific World Journal
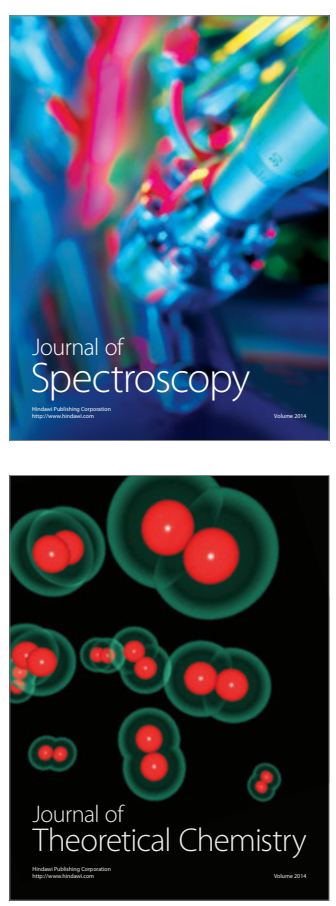
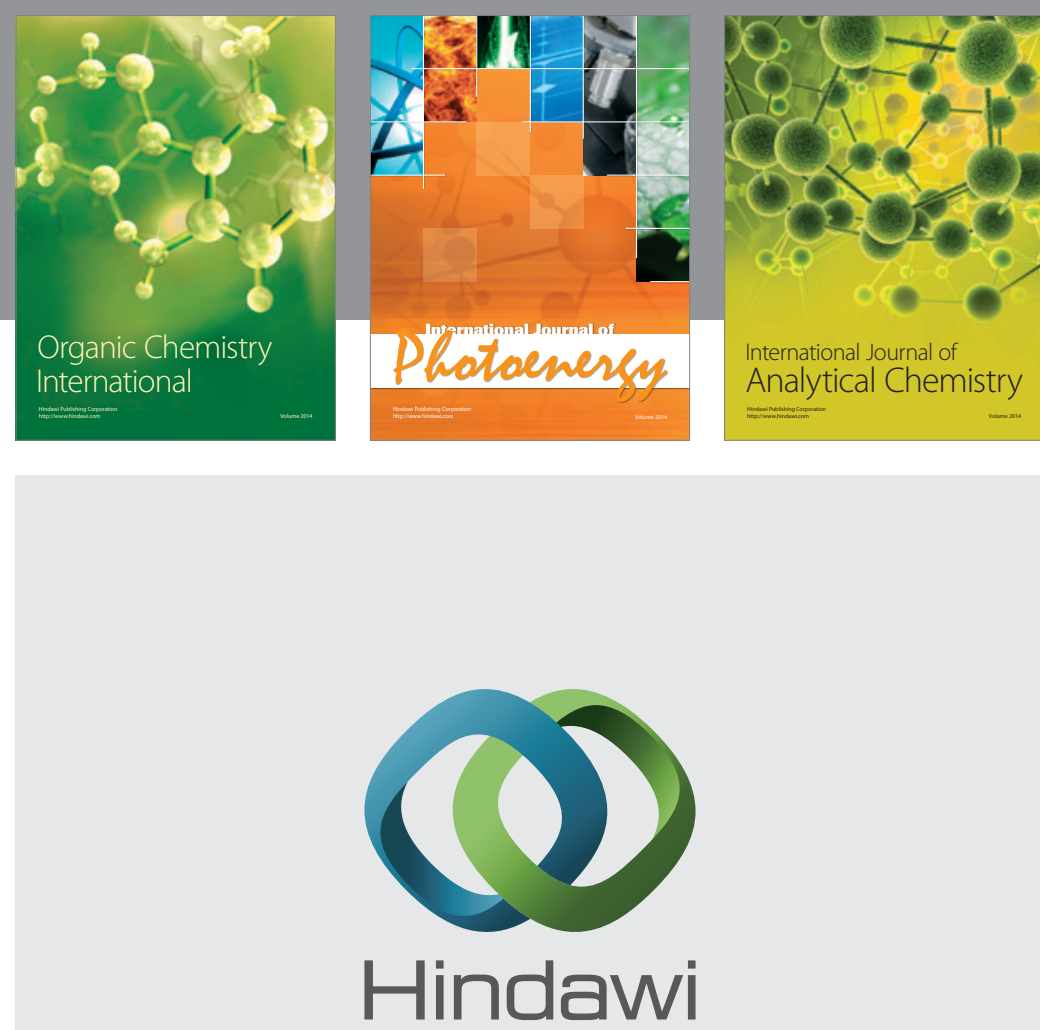

Submit your manuscripts at

http://www.hindawi.com
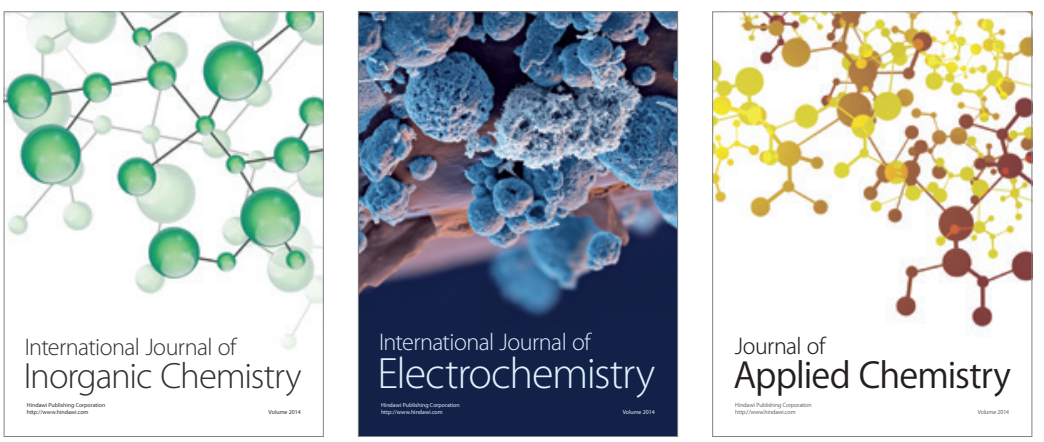

Journal of

Applied Chemistry
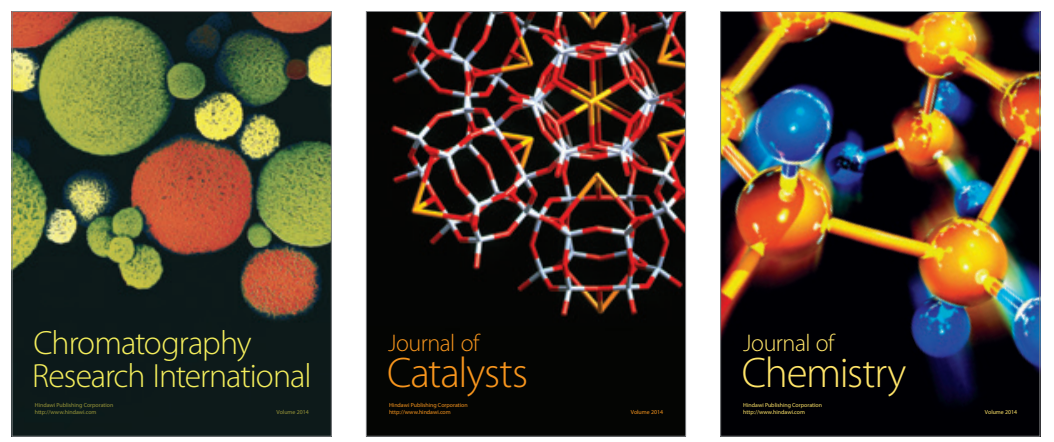
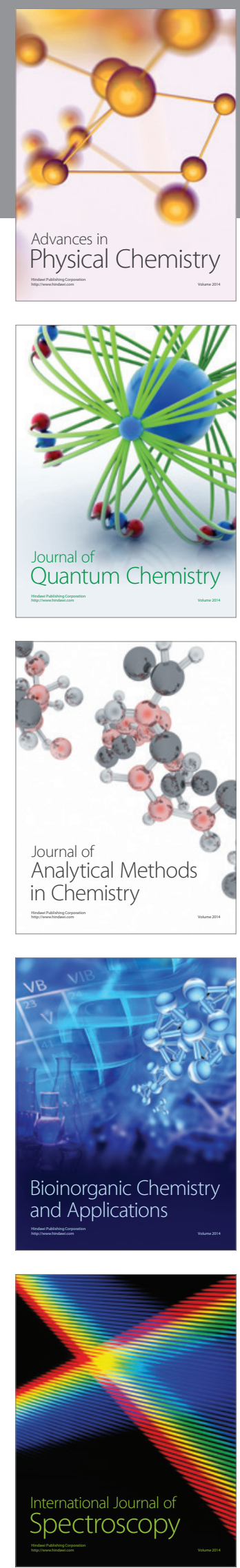